\title{
Initiation and maintenance of breastfeeding: the need for essential support
}

Breastfeeding has proven health benefits for infants and their mothers and economic benefits for the family and society. Therefore, the World Health Organization and other key agencies have recommended exclusive breastfeeding for the first 6 months of an infant's life [1, 2]. To provide essential support to initiate and maintain breastfeeding requires an understanding of the factors associated with parents' choices for starting and maintaining breastfeeding.

Factors influencing the initiation of breastfeeding include maternal characteristics: maternal education attainment [3], marital status, education attainment, smoking, participation in an education program for nutritional supplements for mothers, infants, and children [4], unwanted pregnancies [5], delivery of a low birth-weight infant [6], and postpartum depression [7]. Therefore, it is important to consider these factors in the design of reasonable access to breastfeeding support services and better targeting [8-10].

Alhaji et al. have reported in this issue a study of the outcomes of paid maternity leave on the maintenance of exclusive breastfeeding in Brunei [11]. Implementing a new maternity leave regulation to extend paid maternity leave in Brunei (effective January 2011) moderately increased exclusive breastfeeding at 6 months of infant age by 12 percentage points, from $29 \%$ in 2010 to $41 \%$ in 2013 . The increase was seen in both mothers employed by the government and those employed in the private sector [11]. However, paid maternity leave alone is not sufficient to effect change in exclusive breastfeeding practice, particularly for primiparous mothers, mothers with male infants, and other subgroups such as those with sore nipples and erroneous perception of inadequate milk supply and therefore not meeting the needs of their infants $[12,13]$. Reasons for early termination within the first month of exclusive breastfeeding include sore nipples, perception of inadequate milk supply, and concerns that their infants had difficulty in breastfeeding or were not satisfied by it. Women who choose formula feeding often lack confidence in their ability to breastfeed because of concerns that their infants prefer formula or that they have an inadequate milk supply [14].

The success of exclusive breastfeeding is dependent on health care professionals providing education and support to new parents, and a birthing environment conducive to the initiation of breastfeeding [15]. This education and support should include a combination of pre- and postnatal breastfeeding educational programs, as distinct from either phase alone or onetime intervention. Useful antenatal programs unite education about breastfeeding and behaviorally-oriented counseling; useful maternity care programs include practical skills training and problem-solving, as well as didactic instruction of individuals or small groups by lactation consultants or specially trained nurses, and ongoing postpartum support [15], especially support by peers trained by health professionals [16].

Clinicians from a broad range of disciplines should be encouraged to guide and support exclusive breastfeeding by providing prenatal counseling and educating mothers during hospitalization and after discharge. Guidance and support can be individualized, although postnatal support from community midwife-led groups is effective [17]. Personalized therapeutic drugs and maternal and neonatal conditions should be reviewed to identify and address any potential contraindications of exclusive breastfeeding.

A combined effort from various disciplines based on an understanding of the nature and extent of problems associated with exclusive breastfeeding can be expected to produce a healthier human resource for the world.

*Correspondence to: Editorial Office of Asian Biomedicine, Faculty of Medicine, Chulalongkorn University, Bangkok 10330, Thailand, e-mail: abmjournal@chula.ac.th O Open Access. ๑ 2017 Editorial Office of Asian Biomedicine, published by Sciendo. (๔) BY-NC-ND This work is licensed under the Creative Commons Attribution NonCommercial-NoDerivatives 4.0 License. 


\section{References}

[1] Section on breastfeeding. Breastfeeding and the use of human milk. Pediatrics. 2012; 129:e827-41.

[2] World Health Organization. Global strategy for infant and young child feeding [Internet]. 2017 [cited 2017 Dec 24]. Available from: http://www.who.int/nutrition/publications/infantfeeding/en/index. html

[3] van Rossem L, Oenema A, Steegers EA, Moll HA, Jaddoe VW, Hofman A, et al. Are starting and continuing breastfeeding related to educational background? The generation R study. Pediatrics. 2009; 123:e1017-27.

[4] Centers for Disease Control. Rates of any and exclusive breastfeeding by socio-demographics among children born in 2012. CDC National Immunization Survey [Internet]. 2012 [cited 2017 Dec 24]. Available from: http://www.cdc.gov/breastfeeding/data/NIS_data/index.htm

[5] Taylor JS, Cabral HJ. Are women with an unintended pregnancy less likely to breastfeed? J Fam Pract. 2002; 51:431-6.

[6] Callen J, Pinelli J, Atkinson S, Saigal S. Qualitative analysis of barriers to breastfeeding in very-low-birthweight infants in the hospital and postdischarge. Adv Neonatal Care. 2005; 5:93-103.

[7] Dennis CL, McQueen K. The relationship between infant-feeding outcomes and postpartum depression: a qualitative systematic review. Pediatrics. 2009; 123:e736-51.

[8] Lind JN, Perrine CG, Li R, Scanlon KS, Grummer-Strawn LM. Racial disparities in access to maternity care practices that support breastfeeding - United States, 2011. MMWR Morb Mortal Wkly Rep. 2014; 63:725-8.
[9] McKinney CO, Hahn-Holbrook J, Chase-Lansdale PL, Ramey SL, Krohn J, Reed-Vance M, et al.; Community Child Health Research Network. Racial and ethnic differences in breastfeeding. Pediatrics. 2016; 138(pii):e20152388. doi: 10.1542/peds.2015-2388.

[10] Anstey EH, Chen J, Elam-Evans LD, Perrine CG. Racial and geographic differences in breastfeeding - United States, 2011-2015. MMWR Morb Mortal Wkly Rep. 2017; 66:723-7.

[11] Alhaji MM, Roslin S, Kay A, Tuah NAA. Paid maternity leave extension and exclusive breastfeeding practice: evidence from Brunei Darussalam. Asian Biomed (Res Rev News) 2017; 11:435-42.

[12] Ahluwalia IB, Morrow B, Hsia J. Why do women stop breastfeeding? Findings from the pregnancy risk assessment and monitoring system. Pediatrics. 2005; 116:1408-12.

[13] Odom EC, Li R, Scanlon KS, Perrine CG, Grummer-Strawn L. Reasons for earlier than desired cessation of breastfeeding. Pediatrics. 2013; 131:e726-32.

[14] Li R, Fein SB, Chen J, Grummer-Strawn LM. Why mothers stop breastfeeding: mothers' self-reported reasons for stopping during the first year. Pediatrics. 2008; 122(Suppl 2):S69-76.

[15] Centers for Disease Control, Breastfeeding Report Card, 2016 [Internet]. 2016 [cited 2017 Dec 24]. Available from: https://www. cdc.gov/breastfeeding/pdf/2016breastfeedingreportcard.pdf

[16] Hoddinott P, Britten J. Lay support for breastfeeding. Br J Gen Pract. 2006; 56(527):461-2.

[17] Hoddinott P1, Lee AJ, Pill R. Effectiveness of a breastfeeding peer coaching intervention in rural Scotland. Birth. 2006; 33:27-36. 